5 Nov 2014_rbg

\title{
International Journal for Parasitology
}

\section{Low cost whole-organism screening of compounds for anthelmintic activity}

\author{
Sarah Preston ${ }^{\mathrm{a}}$, Abdul Jabbar ${ }^{\mathrm{a}}$, Cameron Nowell ${ }^{\mathrm{b}}$, Anja Joachim ${ }^{\mathrm{c}}$, Baerbel \\ Ruttkowski $^{c}$, Jonathan Baell ${ }^{b}$, Tony Cardno ${ }^{b}$, Pasi K. Korhonen ${ }^{a}$, David \\ Piedrafita ${ }^{d}$, Aaron R. Jex ${ }^{a}$, Andreas Hofmann ${ }^{a, e}$, Robin B. Gasser ${ }^{a, *}$ \\ ${ }^{a}$ Faculty of Veterinary and Agricultural Sciences, The University of Melbourne, Parkville, Victoria \\ 3010, Australia \\ ${ }^{\mathrm{b}}$ Medicinal Chemistry, Monash University Institute of Pharmaceutical Sciences (MIPS), Monash \\ University, Parkville, Victoria 3052, Australia \\ c Institute of Parasitology, Department of Pathobiology, University of Veterinary Medicine \\ Vienna, Veterinaerplatz 1, A-1210 Vienna, Austria \\ ${ }^{d}$ Faculty of Science and Technology, School of Applied and Biomedical Sciences, Federation \\ University, Churchill, Victoria 3842, Australia \\ e Structural Chemistry Program, Eskitis Institute, Griffith University, Brisbane, Queensland 4111, \\ Australia
}


* Corresponding author. Tel: +613-97312283; fax: +613-97312366.

E-mail address: robinbg@unimelb.edu.au (R.B. Gasser) 


\section{ABSTRACT}

Due to major problems with drug resistance in parasitic nematodes of animals, there is a substantial need and excellent opportunities to develop new anthelmintics via genomic-guided and/or repurposing approaches. In the present study, we established a practical and cost-effective whole-organism assay for the in vitro-screening of compounds for activity against parasitic stages of the nematode Haemonchus contortus (barber's pole worm). The assay is based on the use of exsheathed third-stage (xL3) and fourthstage (L4) larvae of $H$. contortus of small ruminants (sheep and goats). Using this assay, we screened a panel of 522 well-curated kinase inhibitors (GlaxoSmithKline, GSK; code: PKIS2) for activity against $H$. contortus by measuring the inhibition of larval motility using an automated image analysis system. We identified two chemicals within the compound classes of biphenyl amides and pyrazolo[1,5-]pyridines, which reproducibly inhibit both $\mathrm{XL} 3$ and $\mathrm{L} 4$ motility and development, with $\mathrm{IC}_{50} \mathrm{~S}$ of $14-47 \mu \mathrm{M}$. Given that these inhibitors were designed as anti-inflammatory drugs in humans, and fit the Lipinski rule-of-five (including bioavailability), they show considerable promise for hit-to-lead optimisation and repurposing for use against parasitic nematodes. The screening assay established here has significant advantages over conventional methods, particularly in terms of ease of use, throughput, time and cost. Although not yet fully automated, the current assay is readily suited to the screening of hundreds of compounds for subsequent hit-to-lead optimisation and effective repurposing and development. The current assay is highly adaptable to many parasites of socioeconomic importance, including those causing neglected tropical diseases. This aspect is of major relevance, given the urgent need to deliver the goals of the London Declaration through the rapid and efficient repurposing of compounds in public-private partnerships.

\section{Keywords:}

Haemonchus contortus

Anthelmintic screening

Motility assay

Automated imaging analysis

Kinase inhibitor

Biphenyl amide

Pyrazolo[1,5]pyridine 


\section{Introduction}

Parasitic diseases cause substantial morbidity and mortality in animals and people worldwide, and also major losses to the global food production annually. For instance, haemonchosis is one of the most important parasitic diseases of livestock worldwide, affecting hundreds of millions of small ruminants (including sheep and goats), and causing deaths and substantial production losses (Waller et al., 2005; Roeber et al., 2013) estimated at tens of billions of dollars per annum. The causative agent, Haemonchus contortus (barber's pole worm; Nematoda: Strongylida), feeds on blood in the stomach and causes gastritis, anaemia and associated complications, leading to serious production losses and death in severely affected animals. This nematode is transmitted orally from contaminated pasture to the host though a complex life cycle (Veglia, 1915): eggs are excreted in host faeces; the first-stage larva (L1) develops inside the egg to then hatch (usually within 1 day) and develop through to the second- and third-stage larval stages (L2s and L3s) in about a week; the infective L3s are then ingested by the host, exsheath (xL3) and, after a histotrophic phase, develop through fourth-stage larvae (L4) to dioecious adults (within 3 weeks) in the abomasum.

Although a vaccine (Barbervax ${ }^{\circledR}$, Wormvax, Australia) has been released (Oct. 2014) to support treatment programs against haemonchosis, the control of $H$. contortus and numerous other, related nematodes has largely relied on the use of anthelmintic drugs. The excessive use of such drugs has led to widespread resistance in these nematodes to most classes of anthelmintic drugs (Prichard, 1994; Jackson and Coop, 2000; Kaplan, 2004; Wolstenholme et al., 2004; Jabbar et al., 2006; Besier, 2007; Kaplan and Vidyashankar, 2012; Wolstenholme and Kaplan, 2012; Scott et al., 2013), seriously compromising the control of parasites in many countries. Although the development of the compound monepantel (Kaminsky et al., 2008; Prichard and Geary, 2008) has provided fresh hope for the design of new classes of nematocides, success in discovering new drugs using conventional screening (such as larval development, motility and migration inhibition methods; Le Jambre, 1976; Martin and Le Jambre, 1979; Dobson et al., 1986; Kotze et al., 2006; Demeler et al., 2010) has been limited; most assays are not suitable for the efficient and effective screening of chemical libraries, mainly due to the subjective and manual recording of nematocidal activity (e.g., motility or larval development) as well as restrictions on throughput capacity (Geary et al., 2012; Paveley and Bickle, 2013). Nonetheless, there have been some recent improvements in the development of screening assays for parasitic nematodes (Smout et al., 2010; Marcellino et al., 2012; Paveley and Bickle, 2013) but often the financial costs of setting up automated assays can be quite high.

Recent investigations of the genome and transcriptomes of $H$. contortus (see Laing et al., 2013; Schwarz et al., 2013), which are considerably improving our understanding of the molecular biology and biochemistry of this and related strongyloid nematodes, might now support the search for new drugs through target prioritization in silico (e.g., Crowther et al., 2010; Doyle et al., 2010; Jex et al., 2011; Schwarz et al., 2013; Taylor et al., 2013). For instance, based on gene essentiality predictions, Schwarz et al. (2013) predicted and prioritised various ion channels, G-protein coupled receptors, GTPases, peptidases, phosphatases and kinases as drug target candidates. Complemented by such genomic-guided prioritization, the repurposing (repositioning or re-profiling) of existing and/or curated drugs (Emig et al., 2013; Panic et al., 2014) is also likely to accelerate/assist the drug development process particularly through an availability of preclinical data sets for such drugs and the reduced cost, risk and time for translation to market (Panic et al., 2014). In the present study, to overcome limitations of some conventional drug screening methods, we established a new and inexpensive whole-organism assay for the rapid screening of compounds predicted to bind prioritized drug targets (specifically kinases) and destined for repurposing through a public-private partnership. This assay, which relies on video capture to measure the motility inhibitory properties of compounds on the parasitic larval stages ( $x \mathrm{~L} 3 \mathrm{~s}$ and L4s) 
of $H$. contortus and subsequent morphological assessment of larval development, was employed specifically to identify kinase inhibitors with activity against $H$. contortus.

\section{Materials and methods}

\subsection{Production of parasite and storage}

Haemonchus contortus (Haecon-5 strain; cf. Schwarz et al., 2013) was maintained in experimental sheep as described previously (Schwarz et al., 2013) and in accordance with the institutional animal ethics guidelines (permit no. 1111938, The University of Melbourne). In brief, helminth-free Merino sheep (eight weeks of age) were inoculated intra-ruminally with 5,000 third-stage larvae (L3s) of $H$. contortus. Four weeks after infection, faecal samples were collected each day. L3s were produced from eggs by incubating faeces at $27^{\circ} \mathrm{C}$ for one week (Schwarz et al., 2013). Then, L3s were sieved through two layers of nylon mesh (pore size: $20 \mu \mathrm{M}$; Rowe Scientific, Australia) to remove debris or dead larvae, and stored at $10^{\circ} \mathrm{C}$ for up to three months.

\subsection{Exsheathment of $L 3 \mathrm{~s}$}

L3s were exsheathed and sterilised by incubation in $0.15 \% \mathrm{v} / \mathrm{v}$ sodium hypochlorite $(\mathrm{NaClO})$ at $37{ }^{\circ} \mathrm{C}$ for 20 min (Nikolaou et al., 2002) with minor modifications; Following this incubation, exsheathed L3s $(x L 3 s)$ were immediately washed five times in sterile saline by centrifugation at $600 \times \mathrm{g}(5 \mathrm{~min})$ at room temperature $\left(22-24{ }^{\circ} \mathrm{C}\right)$. After the last wash, $x \mathrm{~L} 3 \mathrm{~s}$ were immediately suspended in Luria Bertani medium (LB) [10 g tryptone (cat no. LP0042; Oxoid England), $5 \mathrm{~g}$ yeast extract (cat no. LP0042; Oxoid), $5 \mathrm{~g} \mathrm{NaCl}$ (cat no. K43208004210; Merck, Denmark) in 1 I of reverse-osmosis deionised water]. LB was autoclaved and supplemented with final concentrations of $100 \mathrm{IU} / \mathrm{ml}$ of penicillin, $100 \mu \mathrm{g} / \mathrm{m}$ of streptomycin and 2.5 $\mu \mathrm{g} / \mathrm{mL}$ of amphotericin (Fungizone ${ }^{\circledR}$, antibiotic-antimycotic, cat no. 15240-062, Gibco); this supplemented LB was designated LB*. For experiments involving $L 4, x L 3$ were resuspended in $50 \mathrm{ml}$ of LB* and transferred into a T175 tissue culture flask (DB Falcon, USA). The larvae were then incubated in a water-jacketed CO2 incubator (model no. 2406 Shel Lab, USA) for 7 days at $38{ }^{\circ} \mathrm{C}$ and $20 \% \mathrm{v} / \mathrm{v} \mathrm{CO}_{2}$ to promote development into L4.

\subsection{Preparation of compounds for screening and assay plate preparation}

The compound library (designated PKIS2) containing 522 kinase inhibitors was donated by GlaxoSmithKline (GSK). Compounds were supplied at a concentration of $10 \mathrm{mM}$. Individual compounds were diluted to $40 \mu \mathrm{M}$ in LB* containing 1\% dimethyl sulfoxide (DMSO; cat no. 2225; Ajax Finechem) and dispensed in $50 \mu$ linto the wells of sterile 96-well flat bottom microplates (cat no. 3635; Corning 3650, Life Sciences) using a liquid handler (JANUS, Perkin Elmer). The anthelmintics moxidectin (Cydectin ${ }^{\circledR}$, 
Virbac, France) and monepantel (Zolvix ${ }^{\circledR}$, Novartis Animal Health, Switzerland) were used as positivecontrol compounds.

\subsection{Screening assay to test the effect of compounds on $x L 3$ motility}

On each 96-well plate, test compounds, the positive-control compounds (moxidectin and/or monepantel) and the DMSO control in LB* were arrayed in triplicate. Six wells were used for the negative control (LB* + 1\% DMSO). Following dispensing into the plates, $300 \times \mathrm{L} 3 \mathrm{~s}$ in $50 \mu \mathrm{l}$ of LB* were transferred to each well of each plate (with the exception of perimeter wells) using a multi-channel pipette (Finnpipette ${ }^{\mathrm{TM}}$, Thermo Scientific). During dispensing, xL3s were kept in a homogenous suspension by bubbling air through the solution using an air pump (Airpump-S100; Aquatrade, Australia). Thus, following the addition of $x \mathrm{~L} 3 \mathrm{~s}$ to individual wells, the final concentrations were $20 \mu \mathrm{M}$ (compound) and $0.5 \%$ (DMSO).

Plates were incubated in a water-jacketed $\mathrm{CO}_{2}$ incubator (model no. 2406 Shel Lab, USA) at $38{ }^{\circ} \mathrm{C}$ and $10 \% \mathrm{v} / \mathrm{v} \mathrm{CO}_{2}$. After $72 \mathrm{~h}$, the plates were agitated (126 rotations per min) using an orbital shaker (model EOM5, Ratek, Australia) for $30 \mathrm{~min}$ at $38^{\circ} \mathrm{C}$. In order to capture the motility of xL3s at $72 \mathrm{~h}$, a $10 \mathrm{sec}$ video recording was taken of each well on each plate using an eyepiece camera (Dino-eye, ANMO Electronic Corporation, Taiwan) attached to a stereo dissecting microscope (Olympus, Japan). After 3 min of imaging, plates were re-agitated for $5 \mathrm{~min}$. The motility of xL3s was recorded in each well on each plate (Fig. 1). Each $10 \mathrm{sec}$ video capture of each well on each plate was processed using a custom macro in the program Image J (1.47v, imagej.nih.gov/ij). In each well, changes in light intensity recorded during the $10 \mathrm{sec}$ capture were transformed into a motility index (designated Mi) (Fig. 1). This index was calculated as follows: (i) An image blur (Gaussian normalisation; pixel size 2) was applied to each digitised frame of each video (Fig. 1). (ii) The 100-frame video recording was transformed into a projection-stack; for each pixel ( $n=1$ to $n=12228800)$, the standard deviation of light intensity (LI) was calculated for 50 frames. This was conducted in a 'rolling' manner, starting at frame-(F) one_(F1) and continuing to frame $50(\underline{F 5})$, and then from frame two to frame 51 , etc., for the entire 100 frame projection-stack. (iii) For each pixel, the standard deviation of $\mathrm{LI}$ was then calculated from the standard deviation for each set of 50 frames. These values represented the change in intensity over the 100 frames per pixel and were then displayed in a heat map containing pixels with small (dark blue) to large (red) changes in intensity. The mean of the standard deviation of each pixel (above background) was calculated, in order to compute the final Mi-value for each well; the minimum motility value (i.e. background relating to movement artefacts) per well was set at 25 .

2.5. Assessment of the effect of compounds on the motility and development/growth of fourth-stage larvae (L4)

The motility of L4s was assessed using the same protocol as for $\mathrm{xL3}$ (see subsection 2.4). Following the measurement of $x \mathrm{~L} 3$ motility, plates were re-incubated for four more days in a humidified environment (water-jacketed $\mathrm{CO}_{2}$ incubator) at $38{ }^{\circ} \mathrm{C}$ and $10 \% \mathrm{v} / \mathrm{v} \mathrm{CO}_{2}$. Then, worms were fixed with 50 $\mu \mathrm{l}$ of $1 \%$ iodine, and 30 worms from each well were examined at $20 x$ magnification (DP26 camera, 
Olympus, Japan) to assess their development (based on the presence/absence of a well-developed pharynx characteristic of $H$. contortus L4s; see Sommerville 1966) and growth (according to maximum L4 width measured). The number of $L 4 \mathrm{~s}$ was expressed as a percentage of the total worm number (30). Compounds were tested in triplicate on three different days.

\subsection{Calculation of $I C_{50}$ s of test compounds}

The $\mathrm{IC}_{50} \mathrm{~s}$ were determined for hit compounds by two-fold serial dilution (how many? five times?), starting at a concentration of $100 \mu \mathrm{M}$. Motility of xL3 or L4 was measured at $72 \mathrm{~h}$, and L4 development 7 days after incubation with compounds (subsection 2.5). Compounds were tested in triplicate on three different days.

\subsection{Data analyses}

Raw data were normalised against that of the positive and negative controls to remove plate-to-plate variation by calculating the percentage of motility using the program Prism (v.6 GraphPad Software, USA). Student's t-test was used to establish the appropriate exsheathment rates, storage time and culture medium and whether $0.5 \%$ DMSO had any significant, adverse effect on xL3 motility. Z'-scores (Zhang et al., 1999) were calculated to assess the performance of the screening assay; reliable assays achieve $Z^{\prime}$-scores of between 0.5 and 1 (Zhang et al., 1999). A compound was recorded as having anti-xL3 activity if it reduced motility by $\geq 70 \%$ at $72 \mathrm{~h}$. Compounds with anti-xL3 activity were screened twice at $20 \mu \mathrm{M}$ to verify their inhibitory properties on motility. For compounds that consistently reduced $x \mathrm{~L} 3$ motility by $\geq 70 \%$, dose response curves were produced for $x L 3$ and $L 4$ to establish $I C_{50}$ values. To do this, compound concentrations were $\log _{10}$-transformed, and a variable slope four-parameter equation was used. $I C_{50}$ were also established for $L 4$ development using the same algorithm. A two-way analysis of variance and Dunnett's multiple comparison test was used to compare motility/larval development of compounds at different concentrations and time points during testing in the assay. For statistical analysis of L4 growth, a one-way analysis of variance with a Tukey's multiple comparison test was used to determine statistically significant differences.

\section{Results}

\subsection{Conditions for exsheathment and storage of $L 3 s$, and culturing of $x L 3 s$}

A series of experiments was conducted to establish conditions for the exsheathment and storage of L3s and the culturing of L3s. First, exsheathment of L3s in $0.15 \% \mathrm{NaClO}$ at $37^{\circ} \mathrm{C}$ for 15 and 20 min of incubation was assessed. Incubation for $15 \mathrm{~min}$ achieved an exsheathment rate of $78 \%$ compared with $93 \%$ for $20 \mathrm{~min}$, with no detrimental effect of the longer incubation period on viability; thus, exsheathment was routinely conducted for $20 \mathrm{~min}$. Second, L3s exsheathment was assessed on different batches of L3s stored for 1 and/to 12 weeks at $10{ }^{\circ} \mathrm{C}$, to assess whether a longer storage time has an 
adverse effect on the exsheathment rate. No significant difference in exsheathment was observed between the two storage times, such that L3s used for screening were routinely stored for a maximum of 3 months. Third, xL3 motility in two different culture media was compared between LB*and Dulbecco's Modified Eagle's medium (DMEM). During a period of $24 \mathrm{~h}$, the motility of xL3s incubated in LB*

| (57.66 \pm 2.6$)$ was significantly higher than in DMEM $(32.03 \pm 4.8)(p<0.001)$. Hence LB*_was routinely used for screening.

\subsection{Motility and density of $x L 3 s$ in culture, and assessment of DMSO toxicity}

Another series of experiments was carried out to establish conditions for optimal motility and density of L3s in microculture plates for imaging and toxicity threshold for DMSO. First, we assessed whether the agitation of $x \mathrm{~L} 3$ would achieve suitable motility upon imaging. Second, as $x \mathrm{~L} 3$ s develop to $\mathrm{L} 4 \mathrm{~s}$ in culture $\left(\mathrm{LB}^{*}\right)$ within 7 days at $38^{\circ} \mathrm{C}$, we needed to ensure that lethargus (Veglia 1915), which occurs during the moulting/development process, did not have a confounding effect on motility. Therefore, we assessed what effect agitation of the culture plate for $30 \mathrm{~min}$ prior to imaging would have on motility during imaging. We showed that Mi was significantly higher $(0.5 \pm 0.03)$ with agitation than without $(0.2 \pm 0.03)$ $(p<0.001)$. Third, we established optimal larval density of $x L 3 s$ in wells of the culture plate for imaging. To do this, we established a standard curve for motility using a two-fold serial dilution series (i.e. 500, 250, $125,62,31$ and 15 of $x$ L3s per well). For xL3 densities of $>100 \times$ L3s per well, a signal-to-background ratio of $>1$ was calculated by dividing the $\mathrm{Mi}$ at different densities of $x \mathrm{~L} 3$ by $\mathrm{Mi}$ of wells with no larvae. A density of $300 \times$ L3 per well resulted in the best signal-to-background (noise) ratio $(=7.6)$ and did not result in over-crowding of $x \mathrm{~L} 3 \mathrm{~s}$ within the wells. Fourth, we assessed whether motility was adversely affected by DMSO used to solubilise compounds. Using two-fold serial dilutions from $5.0 \%$ to zero, we showed that DMSO concentrations between $0.3 \%$ and $1.25 \%$ had no significant inhibitory effect on $x \mathrm{~L} 3$ motility (data not shown). Thus, a final DMSO concentration of $0.5 \%$ was selected for solubilisation for routine screening.

\subsection{Establishing $I C_{50}$ values for reference compounds against $x L 3 s$}

The compounds moxidectin and monepantel are routinely used as nematocides. We elected to employ these compounds as positive controls in our assay, because of their (proposed/likely) different modes of action (Campbell et al., 1983; Kaminsky et al., 2008). Using xL3s at a density of 300 per well, we established dose-response curves (titration from 800 to $3.13 \mathrm{nM}$ to by two-fold serial dilutions). In the xL3 motility assay, the $\mathrm{IC}_{50}$ values established for monepantel and moxidectin were $7.14 \mathrm{nM}$ and $2.8 \mathrm{nM}$, | respectively (Supplementary Fig. 1). For ensheathed L3s (is that correct?), $\forall$ under similar conditions (titrating reference anthelmintics from $100 \mu \mathrm{M}$ to $0.15 \mu \mathrm{M}$ ), we calculated $\mathrm{IC}_{50 \mathrm{~s}}$ of $0.4 \mu \mathrm{M}$ and $\mathbf{X} . \mathbf{X X} \mu \mathrm{M}$ for monepantel and moxidectin, respectively, showing that XL3s were at least 187 to $\mathbf{X X}$ times more | sensitive to these two compounds than to (ensheathed) L3s (Supplementary Fig. 1).

3.4. Screening of kinase inhibitors from the PKIS2 library against $x L 3 S$, and assessment on the motility development and growth of $L 4 \mathrm{~s}$

Having established ourthe xL3 motility assay, we proceeded to screen all 522 compounds in the GSK library PKIS2 library twice (on different days in different weeks). Compounds that consistently reduced xL3 motility (in these independent screens) by $70 \%$ at $72 \mathrm{~h}$ were recorded as "hits" (Fig. 2; Table 1; Supplementary Fig. 2). Of all 522 compounds, two chemicals, designated GW800172X and GW461487A, 
reduced $x \mathrm{~L} 3$ motility by $70 \%$ in both the primary and secondary screens (Fig. 2A; Table 1), with Z' scores of $>0.5$ for both screens. Time-course experiments showed a significant decrease in motility for both compounds at $72 \mathrm{~h}(\mathrm{p}<0.05$, Fig. 2B). In addition, dose-response curves established in the $x \mathrm{~L} 3$ motility assay at $72 \mathrm{~h}$ of incubation showed an $\mathrm{IC}_{50}$ of $24 \mu \mathrm{M}$ for compound $\mathrm{GW} 800172 \mathrm{X}$, and $14 \mu \mathrm{M}$ for GW461487A (Fig. 2C; Table 1), employing monepantel and moxidectin as reference/control compounds.

Subsequently, the two compounds GW800172X and GW461487A were tested for their effects on L4 motility and development. Both of these compounds were shown to significantly inhibit L4 motility, with $\mathrm{IC}_{50}$ values of 22 and $47 \mu \mathrm{M}$, respectively (Fig. 2E). There was no significant difference in the inhibition of motility between $x \mathrm{~L} 3 \mathrm{~s}$ and $\mathrm{L} 4 \mathrm{~s}$ despite the dissimilarity in $\mathrm{IC}_{50} \mathrm{~S}$ for compound GW461487A (Table 1). Finally, compounds GW800172X and GW461487A were tested for their ability to reduce the rate of development from xL3 to L4. GW800172X and GW461487A at concentrations of both $25 \mu \mathrm{M}$ and $100 \mu \mathrm{M}$ significantly reduced $L 4$ development by $50 \%$ and by $88-95 \%$, respectively, over 7 days of culturing, with $\mathrm{IC}_{50} \mathrm{~S}$ of 22 and $30 \mu \mathrm{M}$, respectively (Fig. 2E; Table 1; Supplementary Fig 2).

Due to the inhibitory effect of these two compounds on both larval motility and development, the growth of L4s (7 days following treatment with the compounds) was compared with DMSO control larvae (Fig. 2F). Results showed that, while both compounds reduced the width of L4 compared with the DMSO control, only compound GW461487A was found to significantly inhibit growth $(25 \pm 0.5$ to $17 \pm 0.7$, respectively; $p<0.05)$. A reduction in width was reflected by morphological studies where $L 4$ treated with GW461487A induced a shrivelled, dehydrated phenotype similar to the phenotype observed following the treatment of L4 with monepantel (Fig. 2G). No obvious damage to the cuticle of the L4 was observed with following incubation with GW800172X and was similar to the phenotype observed for L4 following treatment with moxidectin (Fig. 2G).

\section{Discussion}

A considerable limitation for the discovery of new anthelmintics or repurposing of existing chemicals as nematocides has been that many screening methods are time-consuming to carry out, lack repeatability/reproducibility or use surrogate organisms, such as Caenorhabditis elegans (Rohwer et al., 2012; Paveley and Bickle, 2013). For instance, the egg hatch test and larval development assay (LDA), which have been effective at finding new nematocides (e.g., monepantel), are usually time consuming, have low reproducibility and use free-living rather than parasitic stages of a nematode. Phenotypic assays that measure a reduction in motility include the larval paralysis test (Martin and Le Jambre, 1979) and larval migration test (Kotze et al., 2006; Demeler et al., 2010) and usually require subjective and labour-intensive phenotypic scoring and manual counting, respectively (Rohwer et al., 2012). The measurement of motility based on object-tracking has been applied to $C$. elegans (www.mbfbioscience.com/wormlab) and Schistosoma mansoni (see Paveley et al., 2012). This tracking approach relies on the digital segmentation of objects from background, which is challenging to perform on parasites, such as $H$. contortus, which are transparent and rapidly translocate across a microscopic field of view (cf. Paveley and Bickle, 2013). Albeit showing promise as a medium to high throughput screening approach, Ameasuring motility through electrical interference negates the use of object segmentation (Smout et al., 2010), shows promise as a medium to high throughput screening approach, butand still needs to be rigorously tested.

Here, we developed a screening assay that overcomes many of these limitations and uses parasitic stages in vitro. The assay relies on the initial use of $\mathrm{xL} 3 \mathrm{~s}$, which means that large stocks of ensheathed $\mathrm{L} 3$ can be stored extended periods of time (at least 3 months at $10^{\circ} \mathrm{C}$ ), with no significant impact on the 
motility of xL3s, which has major advantages over some other assays that rely on fresh materials (e.g., eggs) from infected sheep (Le Jambre 1976; Dobson et al., 1986). The larval motility assay assesses the phenotype of $H$. contortus $x \mathrm{~L} 3$ based on motility, and then assesses the successive development of $x \mathrm{~L} 3$ to L4 (parasitic stages) as well as motility and growth of the L4 stage. To assess larval motility, a low resolution, cost effective video camera (eye piece) is used to capture a $10 \mathrm{sec}$ video of larvae in each well of a 96-well plate, equating to a total of $\sim 20 \mathrm{~min}$ to read one plate. The measurement of motility from the video capture from individual wells is automated, which provides a substantial saving in the operator's time compared with phenotypic scoring by eye (which is intrinsically subjective). As the automated measurement of motility is based on disruptions in light intensity caused by larval movement, the assay is label-free, overcomes the cost and/or complications associated with the use of fluoro-toxic or fluorophores and does not require object-segmentation of individual larvae, which cause problems with image contrast (cf. Paveley and Bickle, 2013). Our approach overcomes these problems as it allows video capture of motility in an entire culture well with (unstained) $300 \mathrm{xL} 3 \mathrm{~s}$ at low magnification. In addition, capturing motility of a large number of individual worms (population) within an individual well reduces bias associated with the use of small numbers of individuals and thus normalises the "overall" motility recorded from a well. Although applied here to $H$. contortus XL3s and L4s, unpublished work indicates that the same approach can be applied to other organisms. The estimated cost of setting up the present assay system (as described here) is estimated at $A \$ 5,000$, with majority of the cost attributed to a computer with a large amount of random access memory (RAM) to capture, process and store video files.

$\mid$

In selecting the present kinase inhibitor set (PKIS2) for screening in ourthis assay, we were guided by evidence from various genomic and transcriptomic studies of nematodes (Jex et al., 2011; Cantacessi et al., 2012; Schwarz et al., 2013; Taylor et al., 2013; Jex et al., 2014; Tang et al., 2014) showing that selected kinase groups, such as those within the MAPK family, likely represent suitable targets for nematodes, such as $H$. contortus and related strongylids, because many of them (i) are known to be essential for growth, development, survival and/or reproduction, (ii) are relatively conserved among nematodes, but (ii) are sometimes divergent from related molecules in other invertebrates and vertebrates (including mammalian hosts). Previously published transcriptional data (Schwarz et al., 2013) also show that the transcription of kinase genes is at its highest during transition from L3 to L4, suggesting that expression is also high during this phase. Of the 522 kinase inhibitors screened in our assaythis study, two inhibitors, designated GW800172X and GW461487A, were identified as "hits" and confirmed as such in subsequent dose response experiments. Temporal assessments showed that both compounds inhibited significantly xL3 motility at $72 \mathrm{~h}$ at a concentration of $20 \mu \mathrm{M}$. Consequently, a $72 \mathrm{~h}$ time point was used to determine the $I_{50} \mathrm{~S}$ in dose response curves. $I C_{50} \mathrm{~S}$ for $\mathrm{GW} 800172 \mathrm{X}$ and GW461487A were 24 and $14 \mu \mathrm{M}$ for xL3 motility, respectively. The IC $\mathrm{C}_{50}$ values of these compounds were comparable for $\mathrm{L} 4$ motility (i.e. 22 and $47 \mu \mathrm{M}$, respectively) and development (i.e. $22 \mu \mathrm{M}$ and $30 \mu \mathrm{M}$, respectively). The morphological examination of larvae showed that, although little loss in the structural integrity of the $x \mathrm{~L} 3$ cuticle was observed following incubation with the compounds, treatment of compound GW461487A on L4 resulted in a shrivelled, dehydrated phenotype. This phenotype was similar to the phenotype observed for L4 treated with monepantel and could be quantitatively | characteriseded by measuring L4 width 7 days following incubation, where GW461487A was found to significantly reduce L4 width compared to the negative control. GW800172X induced a similar phenotype as moxidectin, with little loss in structural integrity of the cuticle. The discrepancies in the observed phenotypes induced post incubation with the compounds may suggest differences in the mode of action to induce inhibition in motility, larval development and growth.

Compounds GW800172X and GW461487A are biphenyl amide and pyrazolo[1,5-]pyridine analogs,

| respectively. Originally, biphenyl amides and pyrazolo[1,5]pyridinesthese chemotypes were developed as therapeutics against inflammatory diseases, such as rheumatoid arthritis, inflammatory bowel disease 
and/or psoriasis to specifically inhibit p38 $\beta$ mitogen activated protein kinases (MAPK) in humans (Lee et al., 1994; Lee and Young, 1996; Pettus and Wurz, 2008; Cheung et al., 2008; Angell et al., 2008a-d); p38 MAPKs are classed as CMGC kinases, and some are described to be involved in the stress and inflammatory signal transduction pathways; proliferation, differentiation and survival in mammals (Cuadrado and Nebreda, 2010); and, interestingly, implicated in innate immunity in the gut of C. elegans (see Troemel et al., 2006). Other studies have reported that p38 MAPK inhibitors can also inhibit the establishment of infections by helminths such as Brugia malayi, Echinococcus multilocularis and $H$. contortus as well as protists including Encephalitozoon cuniculi, Plasmodium falciparum and Toxoplasma gondii (Wei et al., 2002; Wei et al., 2007; Gelmedin et al., 2008; Brumlik et al., 2011; Taylor et al., 2013), supporting the anti-parasitic effect of analogs detected here in $\mathrm{H}$. contortus. Interestingly, Taylor et al. (2013) identified a pyrazolopyrimidine heterocyclic compound, designated DB03023, that induced jerky, twitchy and slow movement phenotypes in C. elegans; DB0323 also inhibited the motility of $H$. contortus L1 (Taylor et al., 2013). Unpublished work has also shown that the structurally similar pyrazol derivative compound-GW461487A which contains a pyrazolo-ring and therefore is structurally similar to that of В80323, also possesses activity against L1s in a conventional LDA for $H$. contortus (cf. Gordon et al., 2014); DB03023 might also have activity against xL3 or L4 H. contortus and thus warrants testing in ourthis newly developed assay. Interestingly, ourthe biphenyl amide analog (GW800172X) did not have any activity on $\mathrm{H}$. contortus L1s in LDA.

Compound GW800172X belongs to a class of biphenyl amide kinase inhibitors, which were discovered by crystallography-based three-3-dimensional pharmacophore-modelling (Angell et al., 2008d) and are selective for the p38 kinase isoforms_p38_ $\beta$. Medicinal chemistry optimisation of initially weaker inhibitors led to GW800172X, with increased potency to inhibit p38 activation (Angell et al., 2008b,c). Selectivity is unusully high for a kinase inhibitor, and a A KINOMEscan (cf. Semenas et al., 2014) of GW800172X against more than 200 kinases showed significant affinity only to $p 38 \beta$. Such unusually high selectivity is a rare observation with kinase ainhibitors andThe selectivity of biphenyl amides for p38 AAPK is believed to be has been attributed to the three aromatic rings associated withwhich give rise to limited "conformational freedom", resulting in the inability of the compounds to bind to kinases with similar binding pockets (Angell et al., 2008d). We have shown that GW800172X has activity against both $\mathrm{xL} 3 \mathrm{~s}$ and L4s of $\mathrm{H}$. contortus. The PKSI2 compound library (GSK) screened here contains nine other biphenyl amides, such as GW810437X and GW595885X which also possessed inhibitory properties on the motility of xL3s, but reducing larval motility only by 44 and $50 \%$, respectively (Fig. 3 ). While a focused analog set is required to better interpretestablish proper structure-activity relationships (SARs) and ultimately obtain more potent compounds, the weaker activity of compounds GW810437X and GW595885X (Fig. 3), both very similar analogs-to GW800172X, suggests an important role for both the aryl methyl group and the cyclopentylamide in inhibiting larval motility in $\mathrm{H}$. contortus.

Compound GW461487A belongs to the pyrazolo[1,5-]pyridines, which were originally produced as potential p38 MAPK inhibitors following the discovery that 2-(4-fluorophenyl)-3-(4pyridinyl)pyrazolo[1,5-]pyridine had anti TNF- properties in vitro and in vivo (Cheung et al., 2008). A series of pyrazolo[1,5-]pyridines were synthesised to further improve the in vivo clearance rate (Cheung et al., 2008). SAR studies have shown that compounds with electron rich-groups attached to the pyrazolopyridine ring, such as compound GW461487A with activity against $H$. contortus, can result in a higher metabolic turnover in liver microsomes (from mouse, rat, dog or human) (Cheung et al., 2008). These authors also showed that in vivo pharmacokinetic profiles (such as bioavailability and half-life) of such compounds could be enhanced by reducing electron density at position 6 of the pyrazolopyridine ring and increasing steric hindrance at position 7 (Cheung et al., 2008). Of the ten other pyrazolo[1,5]pyridines in the present PKSI2 library tested by us (Fig. 4), compounds GW468513X and GW475620X were the only other members of this class in our screen to have any anthelmintic activity, reducing $\mathrm{xL} 3$ motility by some $46 \%$ and $42 \%$, respectively (see Fig. 4). As for GW800172X, a focused analog set around 
GW461487A is required to establish SARs for inhibition of parasitic stages of $H$. contortus, towards next generation compounds with activity at therapeutically adequate levels. However, based on the results obtained with the analogous compounds shown in Fig. 4, we suggest that the 7-methyl is important and that the 4-pyridyl group is preferred over a 4-pyrimidyl group.

At this point, although we can only propose that the two compounds GW800172X and GW461487A target the p38 MAPK in $\mathrm{H}$. contortus, we undertook a preliminary investigation to establish which p38 kinases are encoded in the genome of $H$. contortus. Three p38 MAPKs, called p38 MAP kinase-1 ( $H c$ PMK-1), Hc-PMK-2 and Hc-PMK-3, due to their similarity to $C$. elegans p38 MAPK, were identified (Fig. 5). Like homologs of $C$. elegans (see Berman et al., 2001), Hc-PMK-1 and Hc-PMK-2 are closely related in sequence to those of humans and contains the conserved p38 MAPK threonine-glycine-tyrosine (TGY) motif in the activation loop for the phosphorylation of proteins (see Fig. 5). Hc-PMK-3 is a unique MAPK in that it contains an amino acid substitution of glutamine for glycine at position 556 within the phosphorylation site compared with its human p38 MAPK homologs and similar to that of the p38 MAPK described in C. elegans, Ce-PMK-3 (Berman et al., 2001). Localisation studies in C. elegans have shown that $\mathrm{Ce}$-PMK-1, Ce-PMK-2 and Ce-PMK-3 are expressed throughout the intestine (Berman et al., 2001). In addition, mutagenesis studies demonstrated that the deletion of Ce-pmk-2 results in a larval arrested/death phenotype (Berman et al., 2001), and the removal of Ce-pmk-1 increased susceptibility to bacterial pathogens (Troemel et al., 2006). This information might suggest that the compounds GW800172X and GW461487A target a pathway involving Hc-PMK-1 and/or Hc-PMK-2 in H. contortus and is involved in the substantial inhibition of motility and larval development. Future work should focus on testing this proposal. Although the involvement of Hc-PMK-1 and/or Hc-PMK-2 is hypothetical at this stage, an investigation of the transcriptional profiles of the three p38 PMK isoforms in $\mathrm{H}$. contortus throughout the lifecycle (using data from Schwarz et al. 2013) showed increased transcription of the genes encoding Hc-pmk-1 and Hc-pmk-2 in the parasitic stages (L4s and adults) of this nematode (see Fig. 5). Considering that p38 MAPK signalling in C. elegans is reported to be involved in innate intestinal defence (Troemel et al., 2006), a similar role for $H$. contortus p38 PMK might explain the increased transcription of the genes encoding these proteins as the latter nematode becomes parasitic and adapts to its host environment (Fig. 5). Interestingly, the transcription of the Hc-pmk-3 gene throughout the free-living and parasitic phases of the lifecycle is very low compared with Hc-pmk-1 and Hc-pmk-2, although there are slight differences between the sexes of $H$. contortus, with increased transcription of Hc-pmk-3 in female L4 and adult compared with the male, suggesting a female specific role such as egg production (Fig. 5).

In conclusion, we have established a practical and efficient imaging-based whole-organism assay to screen compounds for activity against parasitic stages of $H$. contortus in vitro. Although not presently in a fully automated, high throughput format, this assay is readily suited to the screening of hundreds of curated and well-defined compounds for subsequent hit-to-lead optimisation, and repurposing and development. It could also be readily applied to assess the nematocidal activity of natural compounds. Importantly, the application of assay identified the two kinase inhibitors GW800172X and GW461487A with anthelmintic properties and potential for lead optimisation. These compounds exemplify several attractive aspects of our approach. First, large numbers of analogs are likely to reside within corporate compound libraries, allowing for the facile establishment of SAR and likely discovery of more potent compounds which are selective for $\mathrm{H}$. contortus and related nematodes compared with human kinases, without requiring any chemistry effort. Second, it is expected that substantial information, such as human pharmacological profile and pharmacokinetic properties, are available for such compounds; for example, both GW800172X and GW461487A have been shown to be amenable to pharmacokinetic | optimization (Angell et al., 2008a-d; Cheung et al., 2008). Third ${ }_{2}$ a major advantage of these chemicals 
over some other presently available anthelmintics is that they should be able to be readily produced in large quantities. For instance, both compounds GW800172X and GW461487A, neither of which is chiral, can be prepared in four, straightforward steps and are well suited for the rapid generation of analogsfocused libraries (Angell et al., 2008a-d; Cheung et al., 2008). This appears to contrast the situation for monepantel (an aminoacetonitrile derivative), for example, whose synthesis requires a multi-step chemical reaction pathway involving the use of sodium cyanide, followed by the isolation of the active optical isomer. Given that the present inhibitors fit the criteria posed for drug-likeness tipinski ('rule-of-five') (Lipinski, 2004) they should now beare worth-while starting points for applicable to-hit-tolead optimisation, wich could be tested againstwith initial validation in $H$. contortus and other parasitic nematodes. Subsequent validation will include, and then following toxicity testing, and assessedment in vivo in sheep or goats against $H$. contortus infection. Although the present study focused on the establishment, evaluation and use of eufa new assay to screen for anti-parasitic activity in a nematode of animal health importance, this present motility-based method is highly adaptable to any parasite of socioeconomic importance, including neglected tropical disease pathogens. This aspect is of majorAs such, the availability of a rapidly deployable whole-organism screening assay presents a pivotal advancementimportance, given the urgent need to achieve some of the goals of the London Declaration (http://unitingtocombatntds.org/resource/london-declaration; 2012) through the rapid and efficient repurposing of compounds within a framework of multiple public-private partnerships.

\section{Acknowledgements}

The present study was funded by the National Health and Medical Research Council (NHMRC) and the Australian Research Council (ARC), and supported by a Victoria Life Sciences Computation Initiative (VLSCl; grant number VR0007) on its Peak Computing Facility at the University of Melbourne, an initiative of the Victorian Government. Animal ethics approval (AEC no. 0707258) was granted by The University of Melbourne. We thank Brendan Ansell for initiating imaging work on worms. We also thank Professor Christian Doerig (Monash University) introducing us to Drs David Drewry and Bill Zürcher (GlaxoSmithKline) who kindly provided us with the PKIS2 compounds. 


\section{References}

Angell, R., Aston, N.M., Bamborough, P., Buckton, J.B., Cockerill, S., deBoeck, S.J., Edwards, C.D., Holmes, D.S., Jones, K.L., Laine, D.I., Patel, S., Smee, P.A., Smith, K.J., Somers, D.O., Walker, A.L., 2008 a. Biphenyl amide p38 kinase inhibitors 3: Improvement of cellular and in vivo activity. Bioorg. Med. Chem. Lett. 18, 4428-4432.

Angell, R.M., Angell, T.D., Bamborough, P., Bamford, M.J., Chung, C.W., Cockerill, S.G., Flack, S.S., Jones, K.L., Laine, D.I., Longstaff, T., Ludbrook, S., Pearson, R., Smith, K.J., Smee, P.A., Somers, D.O., Walker, A.L., 2008b. Biphenyl amide p38 kinase inhibitors 4: DFG-in and DFG-out binding modes. Bioorg. Med. Chem. Lett. 18, 4433-4437.

Angell, R.M., Angell, T.D., Bamborough, P., Brown, D., Brown, M., Buckton, J.B., Cockerill, S.G., Edwards, C.D., Jones, K.L., Longstaff, T., Smee, P.A., Smith, K.J., Somers, D.O., Walker, A.L., Willson, M., 2008c. Biphenyl amide p38 kinase inhibitors 2: Optimisation and SAR. Bioorg. Med. Chem. Lett. 18, 324-328.

Angell, R.M., Bamborough, P., Cleasby, A., Cockerill, S.G., Jones, K.L., Mooney, C.J., Somers, D.O., Walker, A.L., 2008d. Biphenyl amide p38 kinase inhibitors 1: Discovery and binding mode. Bioorg. Med. Chem. Lett. 18, 318-323.

Berman, K., McKay, J., Avery, L., Cobb, M., 2001. Isolation and characterization of pmk-(1-3): three p38 homologs in Caenorhabditis elegans. Mol. Cell. Biol. Res. Commun. 4, 337-344.

Besier, B., 2007. New anthelmintics for livestock: the time is right. Trends Parasitol. 23, 21-24.

Brumlik, M.J., Nkhoma, S., Kious, M.J., Thompson lii, G.R., Patterson, T.F., Siekierka, J.J., Anderson, T.J.C., Curiel, T.J., 2011. Human p38 mitogen-activated protein kinase inhibitor drugs inhibit Plasmodium falciparum replication. Exp. Parasitol. 128, 170-175.

Campbell, W.C., Fisher M.H., Stapley E.O., Albers-Schonberg G., Jacob A.T., 1983. Ivermectin: A potent new anthelmintic agent. Science 221, 823-828.

Cantacessi, C., Campbell, B.E., Gasser, R.B., 2012. Key strongylid nematodes of animals - Impact of nextgeneration transcriptomics on systems biology and biotechnology. Biotechnol. Adv. 30, 469-488.

Cheung, M., Harris, P.A., Badiang, J.G., Peckham, G.E., Chamberlain, S.D., Alberti, M.J., Jung, D.K., Harris, S.S., Bramson, N.H., Epperly, A.H., Stimpson, S.A., Peel, M.R., 2008. The identification of pyrazolo[1,5a]pyridines as potent p38 kinase inhibitors. Bioorg. Med. Chem. Lett. 18, 5428-5430.

Crowther, G.J., Shanmugam, D., Carmona, S.J., Doyle, M.A., Hertz-Fowler, C., Berriman, M., Nwaka, S., Ralph, S.A., Roos, D.S., Van Voorhis, W.C., Agüero, F., 2010. Identification of Attractive Drug Targets in Neglected-Disease Pathogens Using an In Silico Approach. PLoS Negl. Trop. Dis. 4, e804.

Cuadrado, A., Nebreda, A.R., 2010. Mechanisms and functions of p38 MAPK signalling. Biochem. J. 429, 403-417.

Demeler, J., Küttler, U., El-Abdellati, A., Stafford, K., Rydzik, A., Varady, M., Kenyon, F., Coles, G., Höglund, J., Jackson, F., Vercruysse, J., von Samson-Himmelstjerna, G., 2010. Standardization of the larval migration inhibition test for the detection of resistance to ivermectin in gastro intestinal nematodes of ruminants. Vet. Parasitol. 174, 58-64.

Dobson, R.J., Donald, A.D., Waller, P.J., Snowdon, K.L., 1986. An egg-hatch assay for resistance to levamisole in trichostrongyloid nematode parasites. Vet. Parasitol. 19, 77-84.

Doyle, M.A., Gasser, R.B., Woodcroft, B.J., Hall, R.S., Ralph, S.A., 2010. Drug target prediction and prioritization: using orthology to predict essentiality in parasite genomes. BMC Genomics 11, 14712164.

Emig, D., Ivliev, A., Pustovalova, O., Lancashire, L., Bureeva, S., Nikolsky, Y., Bessarabova, M., 2013. Drug Target Prediction and Repositioning Using an Integrated Network-Based Approach. PLoS ONE 8, e60618. 
Geary, T.G., Chibale, K., Abegaz, B., Andrae-Marobela, K., Ubalijoro, E., 2012. A new approach for anthelmintic discovery for humans. Trends Parasitol. 28, 176-181.

Gelmedin, V., Caballero-Gamiz, R., Brehm, K., 2008. Characterization and inhibition of a p38-like mitogen-activated protein kinase (MAPK) from Echinococcus multilocularis: antiparasitic activities of p38 MAPK inhibitors. Biochem. Pharmacol. 76, 1068-1081.

Gordon, C.P., Hizartzidis, L., Tarleton, M., Sakoff, J.A., Gilbert, J., Campbell, B.E., Gasser, R.B., McCluskey, A., 2014. Discovery of acrylonitrile-based small molecules active against Haemonchus contortus. Med. Chem. Comm. 5, 159-164.

Jabbar, A., Iqbal, Z., Kerboeuf, D., Muhammad, G., Khan, M.N., Afaq, M., 2006. Anthelmintic resistance: The state of play revisited. Life Sci. 79, 2413-2431.

Jackson, F., Coop, R.L., 2000. The development of anthelmintic resistance in sheep nematodes. Parasitology 120, S95-S107.

Jex, A.R., Liu, S., Li, B., Young, N.D., Hall, R.S., Li, Y., Yang, L., Zeng, N., Xu, X., Xiong, Z., Chen, F., Wu, X., Zhang, G., Fang, X., Kang, Y., Anderson, G.A., Harris, T.W., Campbell, B.E., Vlaminck, J., Wang, T., Cantacessi, C., Schwarz, E.M., Ranganathan, S., Geldhof, P., Nejsum, P., Sternberg, P.W., Yang, H., Wang, J., Wang, J., Gasser, R.B., 2011. Ascaris suum draft genome. Nature 479, 529-533.

Jex, A.R., Nejsum, P., Schwarz, E.M., Hu, L., Young, N.D., Hall, R.S., Korhonen, P.K., Liao, S., Thamsborg, S., Xia, J., Xu, P., Wang, S., Scheerlinck, J.-P.Y., Hofmann, A., Sternberg, P.W., Wang, J., Gasser, R.B., 2014. Genome and transcriptome of the porcine whipworm Trichuris suis. Nat. Genet. 46, 701-706.

Kaminsky, R., Gauvry, N., Schorderet Weber, S., Skripsky, T., Bouvier, J., Wenger, A., Schroeder, F., Desaules, Y., Hotz, R., Goebel, T., Hosking, B.C., Pautrat, F., Wieland-Berghausen, S., Ducray, P., 2008. Identification of the amino-acetonitrile derivative monepantel (AAD 1566) as a new anthelmintic drug development candidate. Parasitol. Res. 103, 931-939.

Kaplan, R.M., 2004. Drug resistance in nematodes of veterinary importance: A status report. Trends Parasitol. 20, 477-481.

Kaplan, R.M., Vidyashankar, A.N., 2012. An inconvenient truth: Global worming and anthelmintic resistance. Vet. Parasitol. 186, 70-78.

Kotze, A.C., Le Jambre, L.F., O'Grady, J., 2006. A modified larval migration assay for detection of resistance to macrocyclic lactones in Haemonchus contortus, and drug screening with Trichostrongylidae parasites. Vet. Parasitol. 137, 294-305.

Laing, R., Kikuchi, T., Martinelli, A., Tsai, I.J., Beech, R.N., Redman, E., Holroyd, N., Bartley, D.J., Beasley, H., Britton, C., Curran, D., Devaney, E., Gilabert, A., Hunt, M., Jackson, F., Johnston, S.L., Kryukov, I., Li, K., Morrison, A.A., Reid, A.J., Sargison, N., Saunders, G.I., Wasmuth, J.D., Wolstenholme, A., Berriman, M., Gilleard, J.S., Cotton, J.A., 2013. The genome and transcriptome of Haemonchus contortus, a key model parasite for drug and vaccine discovery. Genome Biol. 14, 2013-2014.

Lee, J.C., Laydon, J.T., McDonnell, P.C., Gallagher, T.F., Kumar, S., Green, D., McNulty, D., Blumenthal, M.J., Heys, J.R., Landvatter, S.W., et al., 1994. A protein kinase involved in the regulation of inflammatory cytokine biosynthesis. Nature 372, 739-746.

Lee, J.C., Young, P.R., 1996. Role of CSB/p38/RK stress response kinase in LPS and cytokine signaling mechanisms. J. Leukoc. Biol. 59, 152-157.

Le Jambre, L.F., 1976. Egg hatch as an in vitro assay of thiabendazole resistance in nematodes. Vet. Parasitol. 2, 385-391.

Lipinski, C.A., 2004. Lead- and drug-like compounds: the rule-of-five revolution. Drug Discov. Today: Technol. 1, 337-341.

Marcellino, C., Gut, J., Lim, K.C., Singh, R., McKerrow, J., Sakanari, J., 2012. WormAssay: A novel computer application for whole-plate motion-based screening of macroscopic parasites. PLoS Negl. Trop. Dis. 6, 1-8. 
Martin, P.J., Le Jambre, L.F., 1979. Larval paralysis as an in vitro assay of levamisole and morantel tartrate resistance in Ostertagia. Vet. Res. Commun. 3, 159-164.

Nikolaou, S., Hartman, D., Presidente, P.J.A., Newton, S.E., Gasser, R.B., 2002. HcSTK, a Caenorhabditis elegans PAR-1 homologue from the parasitic nematode, Haemonchus contortus. Int. J. Parasitol. 32, 749-758.

Panic, G., Duthaler, U., Speich, B., Keiser, J., 2014. Repurposing drugs for the treatment and control of helminth infections. Int. J. Parasitol: Drugs Drug Resist. 4, 185-200.

Paveley, R.A., Bickle, Q.D., 2013. Automated Imaging and other developments in whole-organism anthelmintic screening. Parasite Immunol. 35, 302-313.

Paveley, R.A., Mansour, N.R., Hallyburton, I., Bleicher, L.S., Benn, A.E., Mikic, I., Guidi, A., Gilbert, I.H., Hopkins, A.L., Bickle, Q.D., 2012. Whole Organism High-Content Screening by Label-Free, ImageBased Bayesian Classification for Parasitic Diseases. PLoS Negl. Trop. Dis. 6, 1-11.

Pettus, L.H., Wurz, R.P., 2008. Small molecule p38 MAP kinase inhibitors for the treatment of inflammatory diseases: novel structures and developments during 2006-2008. Curr. Top. Med. Chem. 8, 1452-1467.

Prichard, R., 1994. Anthelmintic resistance. Vet. Parasitol. 54, 259-268.

Prichard, R.K., Geary, T.G., 2008. Drug discovery: Fresh hope to can the worms. Nature 452, 157-158.

Roeber, F., Jex, A.R., Gasser, R.B., 2013. Next-generation molecular-diagnostic tools for gastrointestinal nematodes of livestock, with an emphasis on small ruminants: a turning point? Adv. Parasitol. 83, 267-333.

Rohwer, A., Lutz, J., Chassaing, C., Uphoff, M., Heckeroth, A.R., Selzer, P.M., 2012. Identification and profiling of nematicidal compounds in veterinary parasitology. In: Caffrey, C.R (Ed.), Parasitic helminths: targets, screens, drugs and vaccines. Wiley-VCH Verlag GmbH \& Co. KGaA, Weinheim, pp. 135-157.

Schwarz, E.M., Korhonen, P.K., Campbell, B.E., Young, N.D., Jex, A.R., Jabbar, A., Hall, R.S., Mondal, A., Howe, A.C., Pell, J., Hofmann, A., Boag, P.R., Zhu, X.Q., Gregory, T.R., Loukas, A., Williams, B.A., Antoshechkin, I., Brown, C.T., Sternberg, P.W., Gasser, R.B., 2013. The genome and developmental transcriptome of the strongylid nematode Haemonchus contortus. Genome Biol. 14.

Scott, I., Pomroy, W.E., Kenyon, P.R., Smith, G., Adlington, B., Moss, A., 2013. Lack of efficacy of monepantel against Teladorsagia circumcincta and Trichostrongylus colubriformis. Vet Parasitol. 198, 166-171.

Semenas, J., Hedblom, A., Miftakhova, R.R., Sarwar, M., Larsson, R., Shcherbina, L., Johansson, M.E., Härkönen, P., Sterner, O., Persson, J.L., 2014. The role of PI3K/AKT-related PIP5K1 $\alpha$ and the discovery of its selective inhibitor for treatment of advanced prostate cancer. Proc. Natl. Acad. Sci. 111, E3689E3698.

Smout, M.J., Kotze, A.C., McCarthy, J.S., Loukas, A., 2010. A novel high throughput assay for anthelmintic drug screening and resistance diagnosis by real-time monitoring of parasite motility. PLoS Negl. Trop. Dis. 4, 1-10.

Sommerville, R.I., 1966. The development of Haemonchus contortus to the fourth stage in vitro. J. Parasitol. 52, 127-136.

Tang, Y.T., Gao, X., Rosa, B.A., Abubucker, S., Hallsworth-Pepin, K., Martin, J., Tyagi, R., Heizer, E., Zhang, X., Bhonagiri-Palsikar, V., Minx, P., Warren, W.C., Wang, Q., Zhan, B., Hotez, P.J., Sternberg, P.W., Dougall, A., Gaze, S.T., Mulvenna, J., Sotillo, J., Ranganathan, S., Rabelo, E.M., Wilson, R.K., Felgner, P.L., Bethony, J., Hawdon, J.M., Gasser, R.B., Loukas, A., Mitreva, M., 2014. Genome of the human hookworm Necator americanus. Nat. Genet. 46, 261-269.

Taylor, C.M., Martin, J., Rao, R.U., Powell, K., Abubucker, S., Mitreva, M., 2013. Using existing drugs as leads for broad spectrum anthelmintics targeting protein kinases. PLoS Pathog. 9. 
Troemel, E.R., Chu, S.W., Reinke, V., Lee, S.S., Ausubel, F.M., Kim, D.H., 2006. p38 MAPK regulates expression of immune response genes and contributes to longevity in C. elegans. PLoS Genet. 3, 1725-1739.

Veglia, F., 1915. The anatomy and life history of the Haemonchus contortus (Rud.). 3rd and 4th Rep. Dir. Vet. Res., Union S. Afr, 347-500.

Waller, P.J., Chandrawathani, P., 2005. Haemonchus contortus: parasite problem No. 1 from tropics Polar Circle. Problems and prospects for control based on epidemiology. Trop. Biomed. 22, 131-137.

Wei, S., Daniel, B.J., Brumlik, M.J., Burow, M.E., Zou, W., Khan, I.A., Wadsworth, S., Siekierka, J., Curiel, T.J., 2007. Drugs designed to inhibit human p38 mitogen-activated protein kinase activation treat Toxoplasma gondii and Encephalitozoon cuniculi infection. Antimicrob. Agents Chemother. 51, 43244328.

Wei, S., Marches, F., Daniel, B., Sonda, S., Heidenreich, K., Curiel, T., 2002. Pyridinylimidazole p38 mitogen-activated protein kinase inhibitors block intracellular Toxoplasma gondii replication. Int. J. Parasitol. 32, 969-977.

Wolstenholme, A.J., Fairweather, I., Prichard, R., von Samson-Himmelstjerna, G., Sangster, N.C., 2004. Drug resistance in veterinary helminths. Trends Parasitol. 20, 469-476.

Wolstenholme, A.J., Kaplan, R.M., 2012. Resistance to macrocyclic lactones. Curr. Pharm. Biotechno. 13, 873-887.

Zhang, J.H., Chung, T.D., Oldenburg, K.R., 1999. A simple statistical parameter for use in evaluation and validation of high throughput screening assays. J. Biomol. Screen. 4, 67-73. 

Fig. 1. Calculation of the motility index. (i) First, a Gaussian blur is applied to each video. (ii) Then, the frames of the video are transformed into a projection-stack; for each pixel, the standard deviation of light intensity (LI) between frames (F) is calculated. (iii) The change in LI for each pixel is displayed as a heat map, the average change in $\mathrm{LI}$ is calculated, and the background intensity change removed, to yield the final motility index (Mi) score. 
Fig. 2. Screening of PKIS2 compounds for anthelmintic properties. Panel A: Shows selected results (without error bars) from the primary screen of the compound library against the exsheathed third-stage larvae (xL3s) and indicates the performance of the assay ( $Z^{\prime}$-score). Panel B: The inhibitory effects on motility of the hit compounds GW800172X (black closed squares) and GW461487A (grey open squares) at $20 \mu \mathrm{M}$ over time compared to reference anthelmintic compounds monepantel (opened grey triangles) and moxidectin (closed black triangles) and the negative control, LB* $+0.5 \%$ DMSO (closed black circles). *denotes significance for compound GW800172X and " for compound GW461487A where **/\# $p<0.01$. Panels C and D: Dose response profiles of motility inhibition of GW800172X and GW461487A on xL3s and L4s after a $72 \mathrm{~h}$ incubation period. The zero concentration point represents motility when worms are incubated with LB*0.5\%DMSO. Panel E: Dose response profile for hit compounds on the development of the $x \mathrm{~L} 3 \mathrm{~s}$ and the fourth stage larvae (L4s) assessed by the development of a pharynx, following a 7 day incubation period. The zero concentration point represents motility when worms are incubated with LB*0.5\%DMSO. Panel F: Reduction in the width of L4s 7 days post incubation with GW800172X and GW461487A at $100 \mu \mathrm{M}$, * denotes significance difference of $p<0.05$. Panel G: Representative images of larvae (xL3 and L4) following treatment with controls and hit compounds. Scale bar: $50 \mu \mathrm{M}$.

\begin{tabular}{|c|c|c|c|}
\hline $\mathrm{Mi}=17$ & $\mathrm{Mi}=44$ & $\mathrm{Mi}=200$ & $\mathrm{Mi}=109$ \\
\hline $\begin{array}{l}\text { GW800172X: } \\
\mathrm{N}^{3} \text {-cyclopentyl-N }{ }^{4 /}- \\
\text { (cyclopropylmethyl)-6- } \\
\text { methyl-3,4'- } \\
\text { biphenyldicarboxamide }\end{array}$ & $\begin{array}{l}\text { GW810437X: } \\
\mathrm{N}-\left\{4^{\prime}\right. \\
\text { [(cyclopropylmethyl)carbam } \\
\text { oyl]-6-methoxy-3- } \\
\text { biphenylyl\}-3-furamide }\end{array}$ & $\begin{array}{l}\text { GW810445X: } \\
\mathrm{N}^{3} \text {-cyclopropyl-N }{ }^{4}- \\
\text { (cyclopropylmethyl)-6- } \\
\text { fluoro-3,4'- } \\
\text { biphenyldicarboxamide }\end{array}$ & $\begin{array}{l}\text { GW679662X: } \\
\text { N-(Cyclopropylmethyl)- } \\
\text { 2'-methyl-5'-(5-methyl- } \\
\text { 1,3,4-oxadiazol-2-yl)-4- } \\
\text { biphenylcarboxamide }\end{array}$ \\
\hline
\end{tabular}




\begin{tabular}{|c|c|c|c|}
\hline $\mathrm{Mi}=70$ & $\mathrm{Mi}=69$ & $\mathrm{Mi}=124$ & $\mathrm{Mi}=146$ \\
\hline GW775610X : & GW775604X : & GW839464X: & GW702865X : \\
\hline $\begin{array}{l}\text { N-\{4'- } \\
\text { [(cyclopropylmethyl)carbamo } \\
\text { yl]-6-methyl-3-biphenylyl\}-2- } \\
\text { (1- } \\
\text { piperidinyl)isonicotinamide }\end{array}$ & $\begin{array}{l}\mathrm{N}-\{4 \text { - } \\
\text { [(cyclopropylmethyl)carbam } \\
\text { oyl]-6-methyl-3-biphenylyl\}- } \\
\text { 2-(4-methyl-1- } \\
\text { piperazinyl)isonicotinamide }\end{array}$ & $\begin{array}{l}\text { 1-[1-(4-methylphenyl)-3- } \\
\text { (2-methyl-2-propanyl)-1H- } \\
\text { pyrazol-5-yl]-3-\{4-[2-(4- } \\
\text { morpholinyl)ethoxy]-1- } \\
\text { naphthyl\}urea }\end{array}$ & $\begin{array}{l}\text { 2'-methyl-5'-(5-methyl- } \\
\text { 1,3,4-oxadiazol-2-yl)-N- } \\
\{4- \\
\text { [(methylsulfonyl)amino } \\
\text { ]phenyl\}-4- } \\
\text { biphenylcarboxamide }\end{array}$ \\
\hline $\mathrm{Mi}=50$ & $\mathrm{Mi}=92$ & & \\
\hline $\begin{array}{l}\text { GW595885X: } \\
\text { N-(4-methoxyphenyl)-2'- } \\
\text { methyl-5'-(5-methyl-1,3,4- } \\
\text { oxadiazol-2-yl)-4- } \\
\text { biphenylcarboxamide }\end{array}$ & $\begin{array}{l}\text { GW608005X : } \\
\text { 2'-methyl-5'-(5-methyl- } \\
\text { 1,3,4-oxadiazol-2-yl)-4- } \\
\text { biphenylcarboxylic acid }\end{array}$ & & \\
\hline
\end{tabular}

Fig. 3. Chemical structures of the biphenyl amides chemotypes in the published kinase inhibitor set 2 (PKIS2) library. Chemical structures are displayed with the respective motility index (Mi) of individual compounds from the primary screen indicated in the top left-hand corner. The black box highlights the hit compound GW800172X identified during screening. 


\begin{tabular}{|c|c|c|c|}
\hline $\mathrm{Mi}=10$ & $\mathrm{Mi}=46$ & $\mathrm{Mi}=42$ & $\mathrm{Mi}=77$ \\
\hline $\begin{array}{l}\text { GW461487A: } \\
\text { 2-(4-fluorophenyl)-7- } \\
\text { methyl-3-(4- } \\
\text { pyridinyl)pyrazolo[1,5- } \\
\text { a]pyridine }\end{array}$ & $\begin{array}{l}\text { GW468513X: } \\
\text { 2-(4-fluorophenyl)-5- } \\
\text { methyl-3-(4- } \\
\text { pyridinyl)pyrazolo[1,5- } \\
\text { a]pyridine }\end{array}$ & $\begin{array}{l}\text { GW475620X: } \\
\text { 4-fluoro-2-(4- } \\
\text { fluorophenyl)-3-(4- } \\
\text { pyridinyl)pyrazolo[1,5- } \\
\text { a]pyridine }\end{array}$ & $\begin{array}{l}\text { GW515532X : 4-[2-(4- } \\
\text { fluorophenyl)-6- } \\
\text { (trifluoromethyl)pyrazolo[ } \\
\text { 1,5-a]pyridin-3-yl]-N-[3- } \\
\text { (4-methyl-1- } \\
\text { piperazinyl)propyl]-2- } \\
\text { pyrimidinamine } \\
\mathrm{Mi}=70\end{array}$ \\
\hline $\begin{array}{l}\text { GW514786X: } \\
\text { 2-(4-fluorophenyl)-7- } \\
\text { (methylsulfanyl)-3-(4- } \\
\text { pyrimidinyl)pyrazolo[1,5- } \\
\text { a]pyridine } \\
\mathrm{Mi}=107\end{array}$ & $\begin{array}{l}\text { GW468513X: } \\
\text { 2-(4-fluorophenyl)-7- } \\
\text { methoxy-3-(4- } \\
\text { pyridinyl)pyrazolo[1,5- } \\
\text { a]pyridine } \\
\mathrm{Mi}=112\end{array}$ & $\begin{array}{l}\text { GW461484A : } \\
\text { 2-(4-fluorophenyl)-6- } \\
\text { methyl-3-(4- } \\
\text { pyridinyl)pyrazolo[1,5- } \\
\text { a]pyridine } \\
\mathrm{Mi}=166\end{array}$ & $\begin{array}{l}\text { GW514784X: } \\
\text { 2-(4-fluorophenyl)-3-(4- } \\
\text { pyridinyl)-7-(2,2,2- } \\
\text { trifluoroethoxy)pyrazolo[ } \\
\text { 1,5-a]pyridine }\end{array}$ \\
\hline $\begin{array}{l}\text { GW621581X : } \\
\text { 4-[2-(4-fluorophenyl)-6- } \\
\text { (trifluoromethyl)pyrazolo } \\
\text { [1,5-a]pyridin-3-yl]-N-[3- } \\
\text { (4-methyl-1- } \\
\text { piperazinyl)propyl]-2- } \\
\text { pyrimidinamine }\end{array}$ & $\begin{array}{l}\text { GW622475X : } \\
\text { 2-(4-fluorophenyl)-3-(2-\{[3- } \\
\text { (4-methyl-1- } \\
\text { piperazinyl)propyl]amino\}- } \\
\text { 4-pyrimidinyl)pyrazolo[1,5- } \\
\text { a]pyridine-6-carboxamide }\end{array}$ & $\begin{array}{l}\text { GW630813X : } \\
\text { 3-[(4-\{6-(trifluoromethyl)-2- } \\
\text { [3- } \\
\text { (trifluoromethyl)phenyl]pyr } \\
\text { azolo[1,5-a]pyridin-3-yl\}-2- } \\
\text { pyrimidinyl)amino]-1- } \\
\text { propanol }\end{array}$ & \\
\hline
\end{tabular}

Fig. 4. Chemical structures of the pyrazolo[1,5]pyridine chemotypes in the published kinase inhibitor set 2 (PKIS2) library. Chemical structures are displayed, with the respective motility index (Mi) of individual compounds from the primary screen indicated in the top left-hand corner. The black box highlights the hit compound GW461487A identified during screening. 
Fig. 5. Preliminary characterisation of p38 mitogen activated protein kinases (MAPK) isoforms in Haemonchus contortus. Panel A: Phylogenetic analysis of the p38 MAPKs from $H$. contortus, Caenorhabditis elegans, Homo sapiens and Ovis aries. Panel B: Transcription of p38 MAPK homologs throughout the lifecycle of $H$. contortus. Note the increased expression of Hc-pmk-1 and Hc-pmk-2 as $H$. contortus develops through to the parasitic stages. A light colour indicates high transcription. Panel C: Amino acid sequence alignment of the p38 MAPK isoforms in $\mathrm{H}$. contortus (Hc-PMK1-3), C. elegans (CePMK1-3), H. sapiens (MAPKp38/) and O. aries (Oa-MAPK-14). Shaded letters indicate the conserved residues. Black boxes indicate the adenosine triphosphate (ATP) binding region and the activation loop of p38 MAPK kinases. The conserved phosphorylation motif threonine-glycine-tyrosine (TGY) is underlined. Note the threonine-glutamine-tyrosine (TQY) motif in the isoforms $\mathrm{Hc}$-PMK-3 and Ce-PMK-3. 
Supplementary Fig. 1. Panel A: Motility inhibition in response to a two-fold serial dilution of monepantel and moxidectin starting at $800 \mathrm{nM}$ on xL3. Panel B: Comparison of motility inhibition induced by monepantel on ensheathed third stage larvae (L3) and exsheathed thirdstage larva (xL3) of Haemonchus contortus. Panel C: Significant reduction in fourth stage larvae (L4s) development following treatment with $20 \mu \mathrm{M}$ monepantel and moxidectin compared to the negative controls. $* * * *$ denotes $\mathrm{p}<0.0001$ Panel $\mathrm{D}$ : Representative images of $H$. contortus parasitic larvae highlighting the development on the pharynx (black arrow) in L4, which is absent from xL3. Scale bar: $25 \mu \mathrm{M}$.

Supplementary Fig. 2. Video files of exsheathed third-stage larvae (xL3s) and fourth-stage larvae L4 exposed to compounds. 


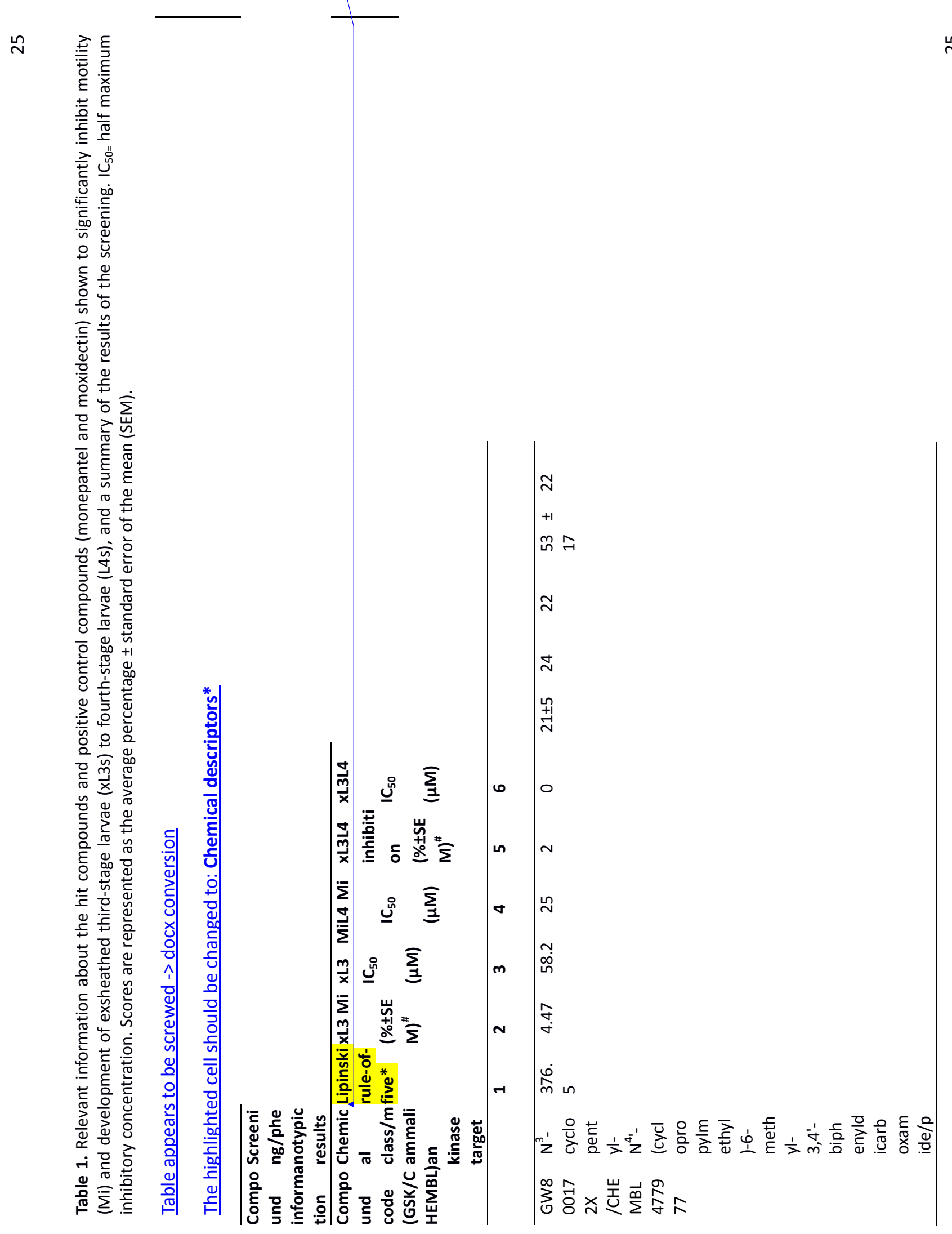




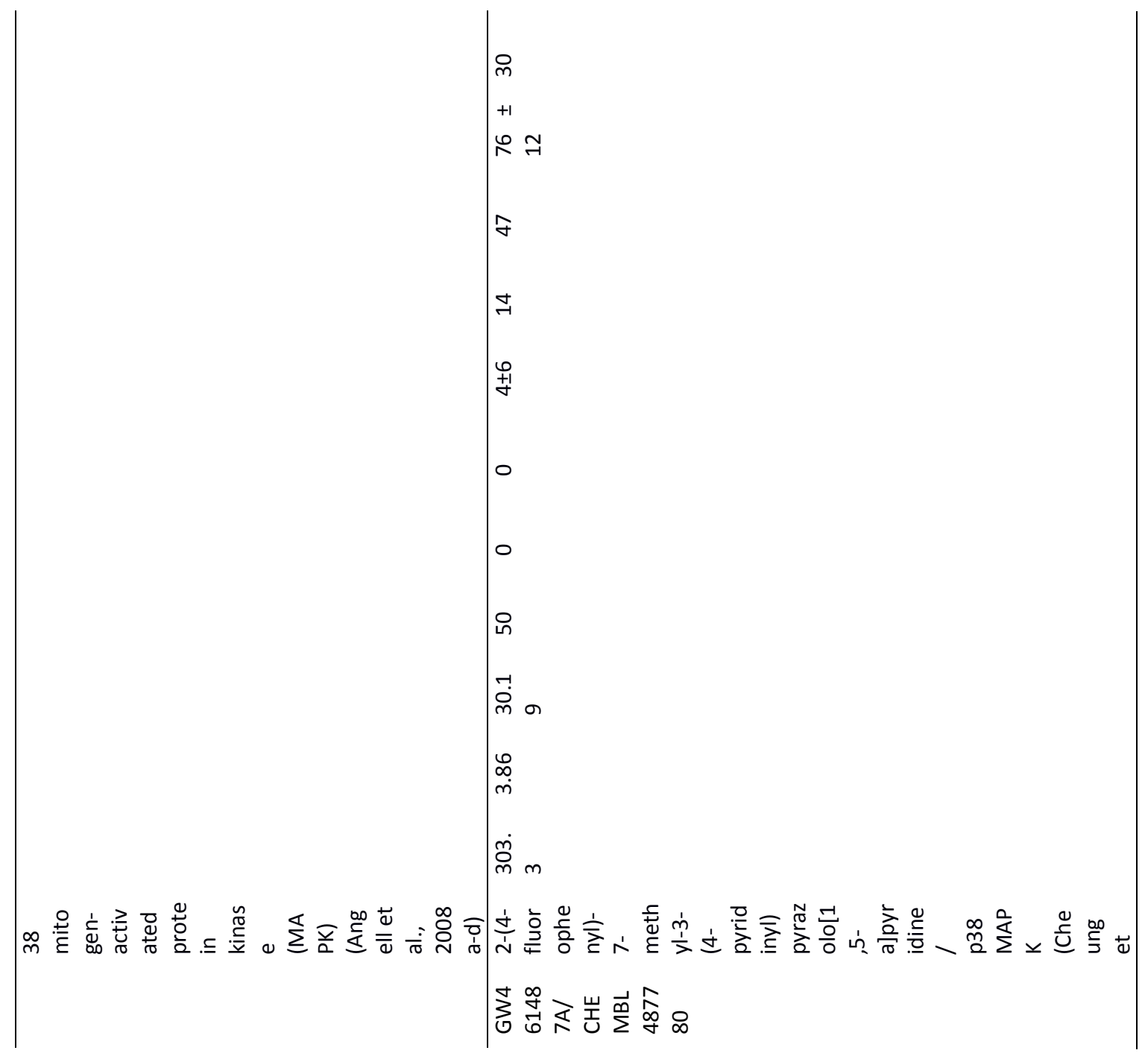




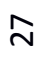

$\lesssim$

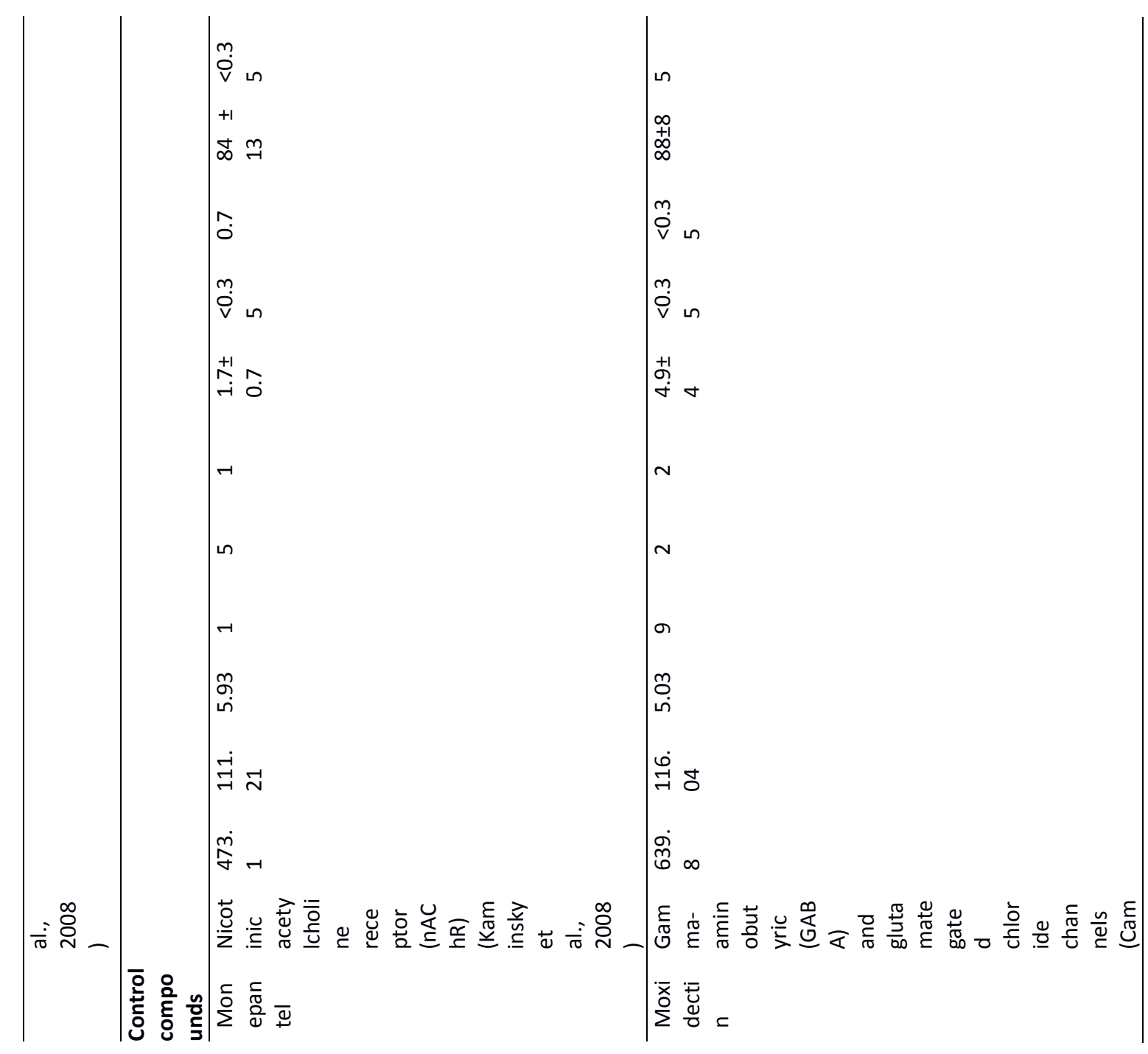




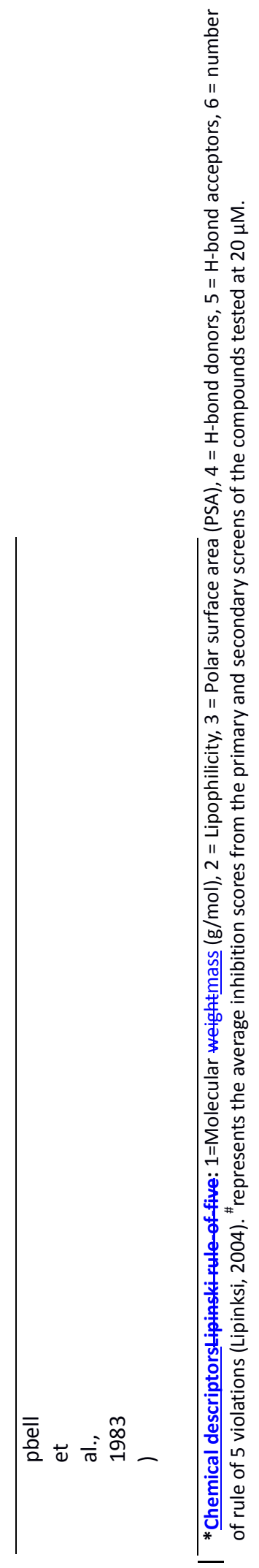

